\title{
BMJ Open Nasal and conjunctival screening prior to refractive surgery: an observational and cross-sectional study
}

\author{
Koji Kitazawa, ${ }^{1,2,3}$ Chie Sotozono, ${ }^{1}$ Masako Sakamoto, ${ }^{4}$ Miho Sasaki, ${ }^{1}$ \\ Osamu Hieda, ${ }^{1}$ Toshihide Yamasaki, ${ }^{3}$ Shigeru Kinoshita ${ }^{1,2}$
}

To cite: Kitazawa $\mathrm{K}$, Sotozono C, Sakamoto M, et al. Nasal and conjunctival screening prior to refractive surgery: an observational and cross-sectional study. BMJ Open 2016;6:e010733. doi:10.1136/bmjopen-2015010733

- Prepublication history for this paper is available online. To view these files please visit the journal online (http://dx.doi.org/10.1136/ bmjopen-2015-010733).

Received 11 January 2016 Revised 21 March 2016 Accepted 19 April 2016

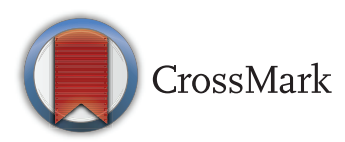

${ }^{1}$ Department of Ophthalmology, Kyoto Prefectural University of Medicine, Kyoto, Japan ${ }^{2}$ Department of Frontier Medical Science and Technology for Ophthalmology, Kyoto Prefectural University of Medicine, Kyoto, Japan ${ }^{3}$ Baptist Eye Clinic, Kyoto, Japan

${ }^{4}$ Research Foundation for Microbial Diseases of Osaka University, Suita, Japan

Correspondence to Dr Koji Kitazawa;

kkitazaw@koto.kpu-m.ac.jp

\section{ABSTRACT}

Objectives: To investigate bacterial flora of clinically healthy conjunctiva and nasal cavity among patients prior to refractive surgery, as well as the characteristics of patients with methicillin-resistant Staphylococcus aureus (MRSA) colonisation.

Design: Observational and cross-sectional study.

Setting: A single-centre study in Japan.

Participants: 120 consecutive patients pre-refractive surgery.

Primary and secondary outcome measures

methods: Samples were obtained from the right conjunctival sac and the nasal cavity of 120 consecutive patients prior to refractive surgery and were then measured for the levels of the minimum inhibitory concentration (MIC) of antibiotics. Patients were interviewed regarding their occupation, family living situation and any personal history of atopic dermatitis, asthma, smoking or contact lens wear.

Results: Propionibacterium acnes (P. acnes) (32.5\%) and Staphylococcus epidermidis (4.2\%) were detected from the conjunctival sac. $S$. epidermidis was the most commonly isolated $(68.3 \%)$ in the nasal cavity. Of the 30 patients $(25.0 \%)$ with colonisation by $S$. aureus, 2 patients, both of whom were healthcare workers with atopic dermatitis, were found to be positive for MRSA in the nasal cavity. A history of contact lens wear, asthma or smoking, as well as patient gender and age, was not associated with MRSA colonisation.

Conclusions: There were only 2 patients who were colonised with MRSA, both of whom were healthcare workers with atopic dermatitis. $P$. acnes was predominantly found in the conjunctival sac. Further study is needed to investigate the involvement between nasal and conjunctival flora, and risk factors for infectious complications.

\section{INTRODUCTION}

Although numerous types of refractive surgery, such as laser in situ keratomileusis (LASIK) and photorefractive keratectomy (PRK), are routinely performed worldwide, infectious keratitis postrefractive surgery is a serious disorder which can rapidly lead to

\section{Strengths and limitations of this study}

Bacterial flora in the conjunctiva and nasal cavity of the 120 patients before refractive surgery were examined.

- The characteristics of methicillin-resistant Staphylococcus aureus (MRSA)-positive patients prior to refractive surgery were examined.

- Small sample size.

- Relatively low rate of positive bacterial growth from the conjunctival sac.

loss of vision. The reported incidence of infectious keratitis postrefractive surgery is relatively low, and ranges between $0.011 \%$ and $0.091 \%$ post-LASIK ${ }^{1-3}$ and between $0.019 \%$ and $0.20 \%$ postsurface ablation. ${ }^{3-5}$ Moreover, the incidence of infectious keratitis postsurface ablation is higher than that of post-LASIK, as epithelial defect and the use of a bandage soft contact lens can increase the risk of infection. Reportedly, fungus, Mycobacterium and Gram-positive bacteria such as methicillin-resistant Staphylococcus aureus (MRSA) are the organisms more likely to cause the infection. ${ }^{6-13}$ The findings of Chang et $\mathrm{al}^{14}$ showed that Mycobacterium was more likely (47 of 103 infections, 45.6\%) than Staphylococcus aureus (S. aureus) (19 of 103 infections, $18.4 \%$ ) to cause infectious keratitis post-LASIK, while findings by de Rojas et $a l^{4}$ and Donnenfeld et al ${ }^{12}$ showed that the most likely microorganism to cause infectious keratitis postsurface ablation was Staphylococcus species, including MRSA. Although Mycobacterium is an organism known to be associated with microkeratome, the frequency of infectious keratitis caused by Mycobacterium is reportedly thought to be on the decrease with the rising popularity of femtosecond laser-assisted refractive surgery, due to its high accuracy and low rate of complications. ${ }^{15}$ Moreover, numerous reports have shown that MRSA-associated keratitis is 
resistant to multiple drugs and is one of the severe complications that can lead to a sight-threatening infection. $^{2} 51012$ 16-22

Chung $e t a l^{23}$ reported that in 105 patients scheduled to undergo refractive surgery, coagulase-negative staphylococci (CNS) was isolated from 73 (85\%), S. aureus was isolated from 2 (2.3\%), Streptococcus pneumoniae was isolated from $1(1.2 \%)$ and Gram-negative bacilli was isolated from $5(4.8 \%)$. In that study, they recommended the use of fourth-generation fluoroquinolones such as gatifloxacin and moxifloxacin, which reportedly have a stronger effect than third-generation fluoroquinolones, such as levofloxacin, ${ }^{24}$ that are commonly used in Japan to prevent postoperative infection. MRSA is an organism that has resistance to these antibiotics and is known to cause severe postoperative infection. It is necessary to find the high-risk patients for MRSA infection. Although preoperative treatments for ocular surface diseases, as well as povidone-iodine and sufficient eyewash during surgery, can result in a reduction of postoperative infections, it is important to elucidate the patients who are at high risk for MRSA infection.

The purpose of the present study was to investigate bacterial flora in the nasal cavity and conjunctival sac among 120 patients prior to refractive surgery and to clarify the carriage rate of MRSA and its risk factor.

\section{METHODS}

In accordance with the tenets set forth in the Declaration of Helsinki for research involving human subjects, written informed consent was obtained from all subjects prior to their participation in the study.

This study involved 120 consecutive patients ( 56 males and 64 females; mean age: $33.2 \pm 8.8$ years $($ mean \pm SD) who underwent an initial medical examination for refractive surgery at the Baptist Eye Clinic between February 2011 and May 2012. The associated refractive surgeries included LASIK, photorefractive keratectomy (PRK) and epithelial LASIK (epi-LASIK). Patients with a history of surgical procedures and those using antibiotic eye drops prior to surgery were excluded from the study. Seventeen patients used artificial tears for dry eye. None of the patients with atopic dermatitis were suffering from severe allergic dermatitis or severe ocular disease. Two cases undergoing antiallergy treatment were included; however, both patients used the treatment for mild allergic conjunctivitis and one patient was not suffering from atopic dermatitis.

Samples were obtained from the right conjunctival sac and nasal cavity of each patient via the rotation of a sterile cotton swab on the day of the initial medical examination, and the collected samples were immediately inoculated in culture medium. The samples from the conjunctival sac were inoculated in aerobic and anaerobic culture, and the samples from the nasal cavity were inoculated only in aerobic culture. These samples were transported to the Research Institute for Microbial Disease at Osaka University, Osaka, Japan. The minimum inhibitory concentrations (MICs) of moxifloxacin (MFLX), cefmenoxime (CMX), erythromycin (EM), chloramphenicol (CP), vancomycin (VCM), oxacillin (MPIPC), cefepime (CFPM) and clarithromycin (CAM) were measured for $S$. aureus. Antibiotics were selected to examine the resistance to multiple drugs, and were not specifically for topical ophthalmic treatment. The fourth-generation fluoroquinolones including MFLX and CMX were basically used as a preoperative and postoperative prophylactic treatment for ocular infection.

On the day of the collection, patients were questioned regarding their occupation, any personal history of atopic dermatitis, asthma and contact lens wear. An additional questionnaire regarding the occupation of the other family members and any history of smoking among the patient and all family members was sent to all of the patients on a different day. Of the 120 patients, 84 answered the additional questionnaire and were analysed.

\section{Statistical analysis}

Statistical analysis was performed using JMP software (V.9.1, SAS Institute, Cary, North Carolina, USA). The relationship between colonisation of MRSA and the characteristics of the patients was then statistically evaluated. Fisher's exact test was used to analyse the obtained data.

\section{RESULTS}

Of the 120 enrolled patients, bacterial growth was identified in the right conjunctival sac of $45(37.5 \%)$ patients and in the nasal cavity of $99(82.5 \%)$ patients.

\section{Colonisation in the conjunctival sac and nasal cavity}

In the conjunctival sac, the following bacteria were found: S. epidermidis (5 patients, 4.2\%), Corynebacterium species (1 patient, 0.8\%), S. aureus (1 patient, 0.8\%), other coagulase-negative staphylococci (CNS) (5 patients, 4.2\%) and Propionibacterium acnes (P. acnes) (39 patients, $32.5 \%$ ) (figure 1). In the nasal cavity, the following bacteria were found: Staphylococcus epidermidis ( $S$. epidermidis) (82 patients, $68.3 \%$ ), Corynebacterium species (35 patients, 29.2\%), S. aureus (30 patients, 25.0\%), $\alpha$-Streptococcus (8 patients, $6.7 \%$ ) and other CNS (16 patients, $13.3 \%)$. In all of the five patients with S. epidermidis in the conjunctival sac, S. epidermidis was observed in the nasal cavity as well.

\section{Susceptibility of $S$. aureus}

We examined the antibiotic susceptibility of $S$. aureus isolated from the conjunctival sac and nasal cavity. $S$. aureus isolated from the conjunctival sac was methicillinsensitive $S$. aureus (MSSA). Among S. aureus isolated from the nasal cavity, 2 strains $(6.7 \%)$ were MRSA and the other 28 strains were MSSA. 
Figure 1 Isolated bacteria from

the nasal cavity (Left) and

conjunctival sac (Right). CNS,

coagulase-negative

staphylococci.
$(\%)$

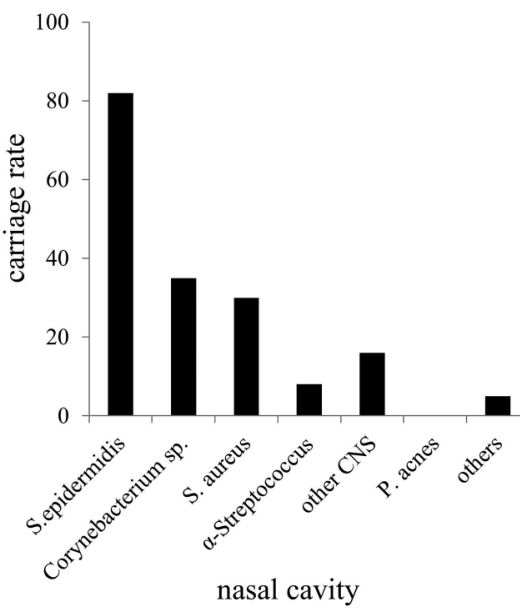

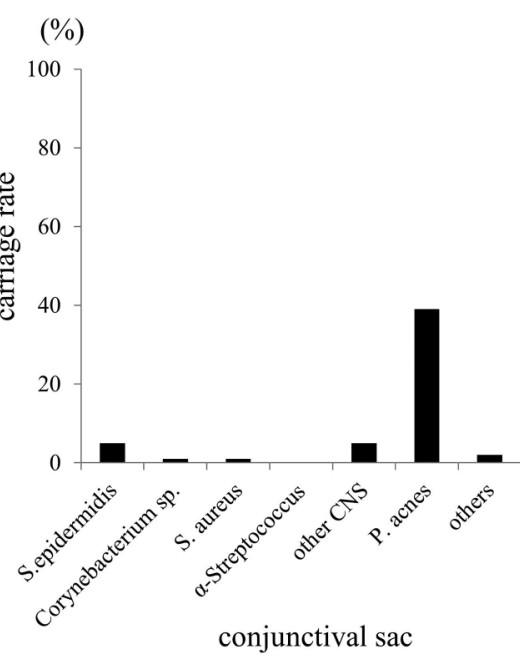

\section{Personal history}

To examine the demographic characteristics of the enrolled patients, each patient was questioned in detail about their personal history. The results of the 120 patients showed that this study included 17 patients (14.2\%) with atopic dermatitis and 10 patients $(22.5 \%)$ with asthma. None of the patients with atopic dermatitis had atopic keratoconjunctivitis or severe allergic inflammation on the ocular surface. Twenty patients $(16.7 \%)$ were healthcare workers, and 105 patients $(87.5 \%)$ had a past history of contact lens wear.

\section{Characteristics of the patients with MRSA}

The demographic characteristics of the patients with or without MRSA in the nasal cavity were examined. No statistically significant differences in age, gender or history of asthma or contact lens wear were found between the patients with and without MRSA colonisation. On the other hand, the carriage rate of MRSA was higher among the healthcare workers (20 patients) than the non-healthcare workers (100 patients) $(\mathrm{p}<0.05)$. MRSA was more frequently found in the patients with atopic dermatitis (17 patients) than in those without atopic dermatitis (103 patients) $(\mathrm{p}<0.05$; table 1$)$. The 2 patients with MRSA colonisation were included in 82 additionally questioned patients. The results showed that MRSA was more frequently found in the patients living with healthcare workers $(p<0.05)$, and that a history of smoking had no relation to MRSA colonisation. MIC values against MFLX, CMX, EM, CP, VCM, MPIPC, CFPM, and CAM for MRSA and the summary of the characteristics of the patients with MRSA colonisation are shown in table 2. The results demonstrated that one of the two MRSA isolates showed a high resistance level to multiple drugs. Of the 2 patients with MRSA colonisation, 1 was a doctor with a medical history of atopic dermatitis and whose family member worked as a nurse. The other patient was a nurse with a medical history of atopic dermatitis and who lived with a family member who was a doctor. These results suggest that risk factors for MRSA colonisation included working at a medical institution, a medical history of atopic dermatitis, and living with a family member who works at a medical institution.

\section{DISCUSSION}

In this cross-sectional study, we examined clinically healthy bacterial flora in the nasal cavity and conjunctival sac among 120 patients prior to refractive surgery. The mean patient age prior to refractive surgery was 33.2 years. MRSA was detected in the nasal cavity of two patients who had a history of exposure to the medical treatment environment and a history of atopic dermatitis.

The most common bacteria isolated in the conjunctival sac was $P$. acnes. CNS was also commonly detected, and the proportion of these bacteria was consistent with that reported in previous studies. ${ }^{23}{ }^{25-27}$ Chung et $a l^{23}$ reported that CNS was the most prevalent microorganism $(85 \%)$ isolated from the conjunctival sac of refractive surgery patients, and that $86(81.9 \%)$ of their patients were positive for bacterial growth, while our findings revealed that there was a relatively low rate $(37.5 \%)$ of positive bacterial growth from the conjunctival sac. However, the longer shipping time, the culture conditions, the culture period and an insufficient rotation of the cotton swab on the conjunctival sac may have contributed to that low positive rate. Although our positive rate of CNS $(4.2 \%)$ in the conjunctival sac was also low compared to the previous report, ${ }^{23}$ it may have been a false-negative rate. In addition, the use of bandage contact lenses post surface ablation may have an effect on the conjunctival flora due to bacterial contamination, ${ }^{28}$ and the differences of postoperative infection needs to be considered between the various surgical procedures.

In the nasal cavity, CNS, Corynebacterium species, and $S$. aureus were the common bacteria isolated. Previous reports have shown that these bacteria were also major 
Table 1 The demographic characteristics of patients with and without methicillin-resistant Staphylococcus aureus in the nasal cavity

\begin{tabular}{|c|c|c|c|}
\hline & $\begin{array}{l}\text { MRSA } \\
(+)\end{array}$ & $\begin{array}{l}\text { MRSA } \\
(-)\end{array}$ & p Value* \\
\hline Number of patients & 2 & 118 & \\
\hline Age (years) & & & NS \\
\hline$\geq 30$ & 1 & 76 & \\
\hline$<30$ & 1 & 42 & \\
\hline Gender & & & NS \\
\hline Male & 1 & 56 & \\
\hline Female & 1 & 62 & \\
\hline Occupation & & & $p<0.05$ \\
\hline Healthcare workers & 2 & 18 & \\
\hline Non-healthcare workers & 0 & 100 & \\
\hline Atopic dermatitis history & & & $p<0.05$ \\
\hline Yes & 2 & 15 & \\
\hline No & 0 & 103 & \\
\hline Asthma history & & & NS \\
\hline Yes & 0 & 10 & \\
\hline No & 2 & 108 & \\
\hline Contact lens history & & & NS \\
\hline Wearer & 1 & 104 & \\
\hline Non-wearer & 1 & 14 & \\
\hline Additional questionnaire & & & \\
\hline Number of patients & 2 & 82 & \\
\hline $\begin{array}{l}\text { Living with healthcare } \\
\text { workers }\end{array}$ & & & $p<0.05$ \\
\hline Yes & 0 & 13 & \\
\hline No & 2 & 69 & \\
\hline Smoking history & & & NS \\
\hline Yes & 0 & 29 & \\
\hline No & 2 & 53 & \\
\hline
\end{tabular}

*Mean Fisher's exact test.

MRSA, methicillin-resistant Staphylococcus aureus.

components of the normal nasal flora. ${ }^{29} 30$ Nasal colonisation is a well-known risk factor for subsequent infection. ${ }^{31}{ }^{32}$ Kimura et $a l^{33}$ also reported a significant relationship between ocular surface colonisation or infection and nasal carriage in patients with MRSA. Actually, S. epidermidis found in the conjunctival sac was observed in the nasal cavity as well. Our findings showed that 2 of the 20 patients who worked as healthcare workers and 2 of the 17 patients with atopic dermatitis were positive for MRSA colonisation in the nasal cavity.
Although MRSA was observed in the nasal cavity alone, the nasal screening might be more sensitive than the conjunctival screening.

MRSA is one of the prominent bacteria that are resistant to multiple drugs. MRSA detected in the two patients in this study were also resistant to multiple drugs, but sensitive to MFLX and CP. Salgado et $a l^{34}$ reported a meta-analysis of the prevalence and the risk factors of MRSA colonisation. The findings of their analysis revealed that most MRSA colonisation develops among those who are in contact with other healthcare workers. Reportedly, the prevalence of nasal MRSA colonisation is $1.5-2 \%$ in the general population. ${ }^{35-37}$ Compared to those surveys, our results showed that MRSA-positive rates (10.0\%) of nasal flora among healthcare workers (20 patients) were significantly high. Atopic dermatitis is also known to be likely colonised with $S$. aureus and MRSA (70-80\% and 11-23\%, respectively), ${ }^{38}$ and the higher severity of atopic dermatitis is associated with $S$. aureus colonisation. ${ }^{40}$ This result was also consistent with the findings in previously published papers. ${ }^{38} 39$ The use of contact lenses or a history of smoking and asthma have also been reported to affect the bacterial flora, ${ }^{41-43}$ yet they had no relation to the MRSA colonisation in this study. Solomon et $a l^{19}$ reported that a multicenter chart review of 13 cases of MRSA keratitis post refractive surgery showed that 13 eyes of 12 patients, 9 of whom were either healthcare workers or exposed to a hospital surgical setting, were at risk for developing MRSA keratitis. Nomi $e t a l^{17}$ reported two cases of MRSA keratitis post-LASIK surgery, whose respective occupations were a doctor and a nurse. We also experienced one case of MRSA keratitis post-epi-LASIK, and her occupation was a nurse.

It should be noted that the sample size in this study was not large, and that at least $240,600,900$ or 1700 samples would need to be included, if the MRSA-positive rates in the healthcare workers were $10 \%$, $5 \%, 4 \%$ or $3 \%$, to achieve a conclusion with statistical significance. However, and at the least, we posit that caution should be taken before recommending healthcare workers with atopic dermatitis for refractive surgery, thus highlighting the need for certain measures to be implemented in order to reduce the risk of severe infection. The screening of nasal and conjunctival flora in

Table 2 The summary of patients with methicillin-resistant Staphylococcus aureus colonisation

\begin{tabular}{|c|c|c|c|c|c|c|c|c|c|c|c|}
\hline \multirow[b]{2}{*}{ Patients } & \multirow[b]{2}{*}{ Occupation } & \multirow{2}{*}{$\begin{array}{l}\text { Occupation } \\
\text { of family }\end{array}$} & \multirow[b]{2}{*}{ History } & \multicolumn{8}{|c|}{ MIC value against each antibiotic } \\
\hline & & & & $\overline{M F L X}$ & CMX & EM & $\mathbf{C P}$ & VCM & MPIPC & CFPN & CAM \\
\hline$\# 1$ & Doctor & Nurse & $\begin{array}{l}\text { Atopic } \\
\text { dermatitis }\end{array}$ & $\leq 0.06$ & 16 & 0.5 & 8 & 1 & 32 & 32 & 0.25 \\
\hline \#2 & Nurse & Doctor & $\begin{array}{l}\text { Atopic } \\
\text { dermatitis }\end{array}$ & 4 & 128 & $>128$ & 8 & 0.5 & $>128$ & $>128$ & $>128$ \\
\hline
\end{tabular}

CAM, clarithromycin; CFPM, cefepime; CMX, cefmenoxime; CP, chloramphenicol; EM, erythromycin; MFLX, moxifloxacin; MICs, minimum inhibitory concentrations; MPIPC, oxacillin; VCM, vancomycin. 
healthcare workers with atopic dermatitis could help to initiate appropriate treatment, not empirical treatment, as soon as possible when infectious keratitis unfortunately occurs postrefractive surgery.

In conclusion, our findings demonstrated that two patients who had MRSA colonisation in the nasal cavity among 120 patients prior to refractive surgery were both healthcare workers with atopic dermatitis. Further research is needed to investigate the correlation between nasal and conjunctival flora and infectious keratitis postrefractive surgery.

Acknowledgements The authors thank John Bush for his excellent help in the preparation of the manuscript, and they also thank Isao Yokota for professional statistician advice.

Contributors $\mathrm{KK}, \mathrm{CS}, \mathrm{OH}$ and SK were responsible for conception and design of the study. KK, MS and $\mathrm{OH}$ were involved in collection of data. KK, CS, MS, MS and TY were responsible for management of data. KK, CS, MS and MS were responsible for analysis of data. KK, CS and MS interpreted the data. KK and CS were involved in writing of the manuscript. KK, CS, MS, MS, OH, TY and SK approved the final draft of the manuscript. $\mathrm{KK}$ and $\mathrm{OH}$ provided statistical expertise to the study. TY was responsible for provision of patients. CS and SK were responsible for obtaining funding for the study. KK and CS conducted literature search.

Funding This work was supported by an intrahospital research fund from the Baptist Eye Clinic and research funds from the Kyoto Foundation for the Promotion of Medical Science.

Competing interests None declared.

Patient consent Obtained.

Ethics approval The Institution Review Board of Kyoto Prefectural University of Medicine and Baptist Eye Yamasaki Clinic (approval number: C-860).

Provenance and peer review Not commissioned; externally peer reviewed.

Data sharing statement No additional data are available.

Open Access This is an Open Access article distributed in accordance with the Creative Commons Attribution Non Commercial (CC BY-NC 4.0) license, which permits others to distribute, remix, adapt, build upon this work noncommercially, and license their derivative works on different terms, provided the original work is properly cited and the use is non-commercial. See: http:// creativecommons.org/licenses/by-nc/4.0/

\section{REFERENCES}

1. Llovet $F$, de Rojas V, Interlandi $E$, et al. Infectious keratitis in 204 586 LASIK procedures. Ophthalmology 2010;117:232-8.e1-4.

2. Solomon R, Donnenfeld ED, Holland EJ, et al. Microbial keratitis trends following refractive surgery: results of the ASCRS infectious keratitis survey and comparisons with prior ASCRS surveys of infectious keratitis following keratorefractive procedures. J Cataract Refract Surg 2011;37:1343-50.

3. Ortega-Usobiaga J, Llovet-Osuna F, Djodeyre MR, et al. Incidence of corneal infections after laser in situ keratomileusis and surface ablation when moxifloxacin and tobramycin are used as postoperative treatment. J Cataract Refract Surg 2015;41:1210-16.

4. de Rojas V, Llovet F, Martínez M, et al. Infectious keratitis in 18,651 laser surface ablation procedures. J Cataract Refract Surg 2011;37:1822-31.

5. Wroblewski KJ, Pasternak JF, Bower KS, et al Infectious keratitis after photorefractive keratectomy in the United States army and navy. Ophthalmology 2006;113:520-5.

6. Yang KS, Chen YF, Lin KK, et al. Mycobacterium keratitis after laser in situ keratomileusis. Cornea 2005;24:344-6.

7. Solomon A, Karp CL, Miller D, et al. Mycobacterium interface keratitis after laser in situ keratomileusis. Ophthalmology 2001;108:2201-8.
8. Alfonso JF, Baamonde MB, Santos MJ, et al. Acremonium fungal infection in 4 patients after laser in situ keratomileusis. $J$ Cataract Refractive Surg 2004;30:262-7.

9. Sridhar MS, Garg P, Bansal AK, et al. Aspergillus flavus keratitis after laser in situ keratomileusis. Am J Ophthalmol 2000;129:802-4.

10. Rubinfeld RS, Negvesky GJ. Methicillin-resistant Staphylococcus aureus ulcerative keratitis after laser in situ keratomileusis. $J$ Cataract Refract Surg 2001;27:1523-5.

11. Moshirfar M, Mirzaian G, Feiz V, et al. Fourth-generation fluoroquinolone-resistant bacterial keratitis after refractive surgery. $J$ Cataract Refract Surg 2006;32:515-18.

12. Donnenfeld ED, O'Brien TP, Solomon R, et al. Infectious keratitis after photorefractive keratectomy. Ophthalmology 2003;110:743-7.

13. Karp CL, Tuli SS, Yoo SH, et al. Infectious keratitis after LASIK. Ophthalmology 2003;110:503-10.

14. Chang MA, Jain S, Azar DT. Infections following laser in situ keratomileusis: an integration of the published literature. Surv Ophthalmol 2004;49:269-80.

15. Santhiago MR, Kara-Junior N, Waring GO IV. Microkeratome versus femtosecond flaps: accuracy and complications. Curr Opin Ophthalmol 2014;25:270-4.

16. Forster W, Becker K, Hungermann D, et al. Methicillin-resistant Staphylococcus aureus keratitis after excimer laser photorefractive keratectomy1. J Cataract Refract Surg 2002;28:722-4.

17. Nomi N, Morishige N, Yamada N, et al. Two cases of methicillin-resistant Staphylococcus aureus keratitis after Epi-LASIK. Jpn J Ophthalmol 2008;52:440-3.

18. Rudd JC, Moshirfar M. Methicillin-resistant Staphylococcus aureus keratitis after laser in situ keratomileusis. J Cataract Refract Surg $2001 ; 27: 471-3$

19. Solomon R, Donnenfeld ED, Perry HD, et al. Methicillin-resistant Staphylococcus aureus infectious keratitis following refractive surgery. Am J Ophthalmol 2007;143:629-34.

20. Woodward M, Randleman JB. Bilateral methicillin-resistant Staphylococcus aureus keratitis after photorefractive keratectomy. $J$ Cataract Refract Surg 2007;33:316-19.

21. Magli A, Forte R, Rombetto L, et al. Bilateral methicillin-resistant Staphylococcus aureus keratitis following hyperopic photorefractive surgery. Int Ophthalmol 2012;32:47-9.

22. Solomon R, Donnenfeld ED, Perry HD, et al. Bilateral methicillin-resistant staphylococcus aureus keratitis in a medical resident following an uneventful bilateral photorefractive keratectomy. Eye Contact Lens 2003;29:187-9.

23. Chung JL, Seo KY, Yong DE, et al. Antibiotic susceptibility of conjunctival bacterial isolates from refractive surgery patients. Ophthalmology 2009;116:1067-74

24. Kowalski RP, Dhaliwal DK, Karenchak LM, et al. Gatifloxacin and moxifloxacin: an in vitro susceptibility comparison to levofloxacin ciprofloxacin, and ofloxacin using bacterial keratitis isolates. $\mathrm{Am} \mathrm{J}$ Ophthalmol 2003;136:500-5.

25. Singer TR, Isenberg SJ, Apt L. Conjunctival anaerobic and aerobic bacterial flora in paediatric versus adult subjects. $\mathrm{Br} \mathrm{J} \mathrm{Ophthalmol}$ 1988:72:448-51.

26. Eder M, Fariña N, Sanabria RR, et al. Normal ocular flora in newborns delivered in two hospital centers in Argentina and Paraguay. Graefes Arch Clin Exp Ophthalmol 2005;243:1098-107.

27. McNatt J, Allen SD, Wilson LA, et al. Anaerobic flora of the normal human conjunctival sac. Arch Ophthalmol 1978;96:1448-50.

28. Liu X, Wang P, Kao AA, et al. Bacterial contaminants of bandage contact lenses used after laser subepithelial or photorefractive keratectomy. Eye Contact Lens 2012;38:227-30.

29. Jousimies-Somer HR, Savolainen S, Ylikoski JS. Comparison of the nasal bacterial floras in two groups of healthy subjects and in patients with acute maxillary sinusitis. J Clin Microbiol 1989;27:2736-43.

30. Savolainen S, Ylikoski J, Jousimies-Somer $\mathrm{H}$. The bacterial flora of the nasal cavity in healthy young men. Rhinology 1986;24:249-55.

31. Gupta K, Martinello RA, Young M, et al. MRSA nasal carriage patterns and the subsequent risk of conversion between patterns, infection, and death. PLOS ONE 2013;8:e53674.

32. Kalra L, Camacho F, Whitener $\mathrm{CJ}$, et al. Risk of methicillin-resistant Staphylococcus aureus surgical site infection in patients with nasal MRSA colonization. Am J Infect Control 2013:41:1253-7.

33. Kimura N, Sotozono $\mathrm{C}$, Higashihara $\mathrm{H}$. [Relationship between ocular surface infection or colonization of methicilin-resistance Staphylococcus aureus and nasal carriage]. Nippon Ganka Gakkai Zasshi 2007:111:504-8.

34. Salgado CD, Farr BM, Calfee DP. Community-acquired methicillin-resistant Staphylococcus aureus: a meta-analysis of prevalence and risk factors. Clin Infect Dis 2003;36:131-9. 
35. Leman R, Alvarado-Ramy F, Pocock S, et al. Nasal carriage of methicillin-resistant Staphylococcus aureus in an American Indian population. Infect Control Hosp Epidemiol 2004;25:121-5.

36. Abudu L, Blair I, Fraise A, et al. Methicillin-resistant Staphylococcus aureus (MRSA): a community-based prevalence survey. Epidemiol Infect 2001;126:351-6.

37. Kenner J, O'Connor T, Piantanida N, et al. Rates of carriage of methicillin-resistant and methicillin-susceptible Staphylococcus aureus in an outpatient population. Infect Control Hosp Epidemiol 2003;24:439-44.

38. Suh L, Coffin S, Leckerman $\mathrm{KH}$, et al. Methicillin-resistant Staphylococcus aureus colonization in children with atopic dermatitis. Pediatr Dermatol 2008;25:528-34.

39. Klein PA, Greene WH, Fuhrer J, et al. Prevalence of methicillin-resistant Staphylococcus aureus in outpatients with psoriasis, atopic dermatitis, or HIV infection. Arch Dermatol 1997:133:1463-5.

40. Balma-Mena A, Lara-Corrales I, Zeller J, et al. Colonization with community-acquired methicillin-resistant Staphylococcus aureus in children with atopic dermatitis: a cross-sectional study. Int $J$ Dermatol 2011;50:682-8.

41. Vázquez Nava F, Casados Robledo JS, Béltrán Guzmán FJ. Oropharyngeal bacterial flora in asthmatic and health subjects. Rev Alerg Mex 1998;45:31-5.

42. Choi CS, Yin CS, Bakar AA, et al. Nasal carriage of Staphylococcus aureus among healthy adults. $J$ Microbiol Immunol Infect 2006;39:458-64.

43. Iskeleli $\mathrm{G}$, Bahar $\mathrm{H}$, Eroglu $\mathrm{E}$, et al. Microbial changes in conjunctival flora with 30-day continuous-wear silicone hydrogel contact lenses. Eye Contact Lens 2005;31:124-6. 